\title{
Enhancing Productivity Through Lean Behavior
}

\author{
A. Perumal Puvanasvaran \\ Technical University of Malaysia Malacca \\ Malaysia
}

\section{Introduction}

Productivity is a measure of output from a production process. It reflects the efficiency of production. A change in technology today, however, might increase production output with a given quantity of inputs, such an increase in productivity would be more technically efficient, but might not reflect any change in allocative efficiency. Lean initiatives that focuses on tools and techniques, often stumble as excitement from initial achievements diminishes and the lean way becomes more difficult. Behavioral change is the key to making lean initiatives sustainable and successful. Lean behavior on the other hand, improves the problem solving capabilities of people in the development system while eliminating wastages, reducing cost, increasing efficiency and enhancing productivity.

Furthermore, lean is one of the popular concepts that have been implemented in many companies. According to Bhasin and Burcher (2006), very few companies succeed in implementing lean manufacturing practices. The number of lean tools, techniques and technologies available to improve operational performance is growing rapidly, however a few companies that put effort to use them failed to produce significant results. One of the major reasons for unsuccessful implementation of lean manufacturing is the typical behaviors exhibited by people at the workplace, which are known to be deficient in trust and gain commitment too. Orr (2005) stated that the term "lean" manufacturing seems to have forgotten the debate on human motivation, and has focused on techniques, where the emphasis has been on deploying new methods, rather than understanding how work is organized and lead. The practice of lean behavior is shown to be an essential element for producing healthy work environments that can lead to economic improvement. At the same time, lean produces as stated by Emiliani (1998). Emiliani and Stec (2004) that lean behavior practices must apply all the lean principles where most companies failed to apply all the lean principles together in order to get significant result. It is essential that the right behavior among organization employees is maintained, so that the full benefits of lean can be enjoyed as stated by Sanjay and Peter (2006). Implementation lean is a long journey process and not easily implemented. To fully benefit the company for lean implementation, both the concept and techniques should be considered. Lean behaviors typically are essential factor and should be assessed for a successful and complete implementation.

Thus, it is important to enhance productivity through lean behavior and inspect lean result after implementation of lean. This study will presents the results of the comparison being made between lean behaviors after implementing lean for one year through lean behavior of 
the people in the development system. The importance of the problem solving capabilities of people in implementing lean process management will be also discussed. The survey was to conduct in an aerospace composite manufacturer in their kitting department. Selfadministered questionnaire has been selected to be the survey instrument in enhancing productivity. These questionnaires were distributed to 45 employees working in the kitting department. Results of the findings and feedback are collected and analyzed by using the Statistical Package for Social Science (SPSS) software. The outputs of the analysis were in the form of index values, percentages and hypothesis testing. The result shows the improvement on lean behavior with the help of people development system implementation which enhance the people capabilities in eliminating wastages, reducing cost and increasing productivity. These are supported by comparing the results of surveys on lean behavior for the beginning and end of the year with the monitoring of real life data on the case study.

\section{Lean behavior}

Lean behavior is defined as behaviors that add or create value to waste. It is the minimization of waste associated with arbitrary or contradictory thought and actions that leads to defensive behavior, ineffective relationship, poor co-operation, and negative attitudes stated by M.L. Emiliani (1998). According to case study on Motorola, behavior is important to change culture to sustain implementing of lean concept. Many efforts failed due to the behavior of the management. Employees will follow the management's behavior if they are ordered to do new things. Anonymous, Worley and Doolen (2006) investigated two specific variables impact on lean implementation which is management support and communication. For management support, top management should not only demonstrate commitment and leadership, it must also work to create interest in the implementation and communicate the change to everyone within the organization. Comm (2005) states, that five best practiced components must present in order to apply lean. The five best practiced components are environment change, leadership, culture, employee empowerment, and communication. The management is required to have these lean behaviors which will influence the employees to practice the five components. Meanwhile, Orr (2005) stated that leadership is the fundamental aspect in engaging this different approach in thinking. Leaders are not necessarily top and senior management. Leaders are employees with influence on the work, at whatever level of seniority and responsibility. A leadership must have nine lean behaviors. The nine lean behaviors are teaches and engages workgroups, Respect For people, Process Focus, Support and recognition, Lead by example, Deploy policy and objectives, Commitment to standards, Understand lean vision and principles and Support the change process. Meanwhile, there are other findings on factors that act as barrier for implementing lean concept. Emiliani (1998) stated four primary causes that management lack influence over employees; the four components are the barrier for the commitment of whole employees to implement lean concept. The four components are Trust, Communication, Processes and Environment. Even a case study was conducted by O'hEocha (2000) on Cooke Brother Ltd manufacturing company about the influence of employee's attitudes on the use of $5 S$ which is one of the lean tools for improvement environment management. After the company applies the lean tool in their company, employees were asked to identify the potential issues that may act as barriers to effective implementation. 
A survey was conducted by interviewing the top management, middle management and the shop floor. The top management barrier to implement the tool related to issues of communication and power. There were concerns that middle managers and supervisors may feel threatened by the perceived loss of control as shop floor staffs gain more power to use initiatives and make certain changes without consultation with line managers. Even they felt that there were difficulties when it came to making decisions regarding throwing away certain pieces of equipment and machinery that are very old, do not work and take up valuable space. Middle management representatives commented that the 5Ss started off well but dwindled in certain areas. It was because they lost interest and it fell down on custom and practice/self-discipline. They also felt that they should have more power to make decisions relating to their positions. Shop floor felt that some employees had attitude problems, and put minimum effort into their jobs and were not bothered to use or implement the 5Ss, while others were actively involved. Besides, they also commented that their initiative was sometimes held back by their line managers. It was felt that certain line managers were fearful of their subordinates shining and potentially threatening their position. As a result, they did minimum and took no interest in the initiatives of $5 S$ that were likely to be protected by their line managers. From the survey, it was clear to show that the management behavior is the important barrier to implement the lean tool. In Table 1, lean behaviors practices of impact lean manufacturing are highlighted.

\begin{tabular}{lll}
\hline Authors & Component & Lean Behaviors Practice \\
\hline Worley J.M. and Doolen T.L & i. Management support & - Commitment without fear, respect to people, recognition to people \\
& ii. Communication & - Clear communication \\
\hline Clare L. Comm & i. Environment for change & - Understanding and proactive \\
& ii. Leadership & - Assist and coach employees, responsible \\
& iii. Culture & - Honest and respect to people \\
& iv Employee empowerment & - Given recognition for employees \\
& v. Communication & - Share information, understand the goal \\
\hline Emiliani & i. Trust & - justice without favors some people, meet the promise \\
& ii. Communication & - Clear message, quick feedback, \\
& iii. Processes & - Clear about their responsibilities, follow procedures \\
& iv. Environment & - Given recognition to people, understanding people problem \\
\hline Cameron & i. Leadership & - Teaches and engages workgroups, respect for people, process focus, support \\
& & and recognition, lead by example, deploy policy and objectives, commitment \\
& & to standards, understand lean vision and principles, support the change process \\
\hline
\end{tabular}

Table 1. Component and Lean Behaviors Practice Of Impact Lean Manufacturing

\section{Tips to build lean behavior}

It is a present-day instance of the recurring theme in human history toward increasing efficiency, decreasing waste, reducing cost and using empirical methods to decide what matters, rather than uncritically accepting pre-existing ideas. In order to enhance productivity, we therefore acquire a broader set of skills, creative and innovative approaches to analysis, using up-to-date tools and design through the implementation of lean production methodology and management. As an example, manufacturers must be able to use various of methodologies, ideas and many others of present-day high technology tools to be able to enhance problem productivity and do lean production effectively. Meanwhile, both manufacturers and consumers that comprise the different status levels in the community will have easy and convenience access to the real-time oriented systems for problem solving capabilities and productivity enhancement. For this to occur, tips to build lean behavior are proposed in this chapter for enhancing productivity. 
The organizational vertical integration has parallels input values with other lean disciplines such as lean behaviors are therefore important. Positive organizational behavior which is linked to human resource strengths and psychological capabilities for performance improvement and productivity enhancement in today's workplace. Worker inappropriate behaviors are difficult to change because they are functional: they serve a purpose as an employee. The practice of lean behaviors is shown to be an essential element for producing healthy work environments that can lead to economic growth, as well as help businesses sustain efforts to become lean producers. The principal focus is on how individuals can consistently behave in ways that create value, with the goal of eliminating waste in both intra and interpersonal relationships M.L. Emiliani (1998).

Several tips that leaders can use to improve their team lean behavior. Such as:

1. Defining lean behavior

Most people like to see the correct or the right way of handling work but the correct or right way is not always clear. They might think of doing a right way without looking into lean principals. Lean wants problems and abnormal conditions to be exposed and no wastage nor costliness. Leaders have to make sure that doing the right way doesn't have a high cost to team members.

2. Rewarding who has lean behavior

When the demand for goods is decreasing, workers stop to do overtime. The leader needs to thank to workers for their action. If the workers continue doing their overtime, they are doing it for the wrong reason and that is to increase the overhead cost of the company. Some people like to bypass a process to make things happen quickly. Leader should stop rewarding them of heroism. This might be sending a wrong message.

3. Making system support lean behavior

Leaders must make the workplace look like $5 S$ environment that support lean behavior. Workers will do and follow what the leader normally says. If the workers keep collecting data without analyzing it or no change is being made. Do you think this system support lean behavior? Definitely not! This will lead to wasting of time and expenses.

4. Building up a right lean behavior team

When people see others exhibiting good behavior, they are more likely to continue or follow it. Leaders need to set up a good example of team that can perform good lean behaviors so that others will follow the right steps and procedures.

5. Eliminating problem members in the team

If a member doesn't meet productivity and quality standards after repeated attempts to work with in order to improve, then get a new member. If a customer has expectations that are unreasonable and unprofitable to company, find more customers and nothing to say that you need to deal with them. If an employee chooses not to show lean behavior, they may not be a good match for the team.

\section{Comparison of behavior attributes}

The organizational vertical integration reflects the level of business community that exhibits the most consistent generative behaviors, as well as helpful tendencies, will be the partner of choice for employees, suppliers, customers, and investors. Lean behaviors exhibited by the organization culture should be a strong source of competitive advantage. Table 1a below 
compares common fat behaviors that result in waste and selected lean behaviors that promote flow between people as stated by Cleary (1989) and (1996). It is important to realize that interpersonal skills and organizational effectiveness are developed by practicing and improving upon weaknesses (i.e. lean behaviors), not strengths (i.e. fat behaviors) as mentioned by M.L. Emiliani (1998).

\begin{tabular}{ll}
\hline Fat behaviors & Lean behaviors \\
\hline Confusion & Self-awareness \\
Unnecessary commentary & Humility \\
Irrelevant observations & Compassion \\
Random thoughts & Suspension \\
Self-imposed barriers & Deference \\
Ego & Calmness \\
Irrationality & Quietude \\
Revenge & Reflection \\
Inaction & Honesty \\
Positions & Benevolence \\
Interpretations & Consistency \\
Uncertainty & Generosity \\
Negativity & Patience \\
Excess & Humor \\
Gossip & Understanding \\
Sarcasm & Respect \\
Preoccupation & Listening \\
Ambiguity & Observation \\
Extreme flattery & Trust \\
Cynicism & Sincerity \\
Subjectivity & Equanimity \\
Bias/prejudice & Objectivity \\
Deception & Discipline \\
Selfishness & Rectitude \\
Pride & Wisdom \\
Criticism & Balance \\
\hline
\end{tabular}

Table 1.a Comparison Of Behavior Attributes by Cleary (1989) and (1996).

\section{Do lean behaviors correlate with productivity?}

The answer is probably yes, when we consider the practice of lean behaviors as shown to be an essential element for producing healthy work environments that can lead to productivity growth, as well as help production sustain efforts to become lean producer. The principal focus is on how individuals can consistently behave in ways that create value (lean behavior), with the goal of eliminating waste in interpersonal relationships and development of people that possess basic capabilities for problem solving in their thoughts and actions. If the performance of lean behaviors can be practiced by individuals and then integrated into the organization, the productivity will definitely be enhanced by lean behavior.

Liker (2004) stated about how organization should implement the lean process management, there is no exact definition for a fully lean organization. Even though the goal of becoming a 
fully lean organization can only be reached if the employees are well aligned with new philosophy. In that case, it is important for an organization to understand and apply all lean behavior practices and principles, in addition to a comprehensive lean thinking which affects the whole business model as a key and not solely learner production. Figure 1 shows the key participants in a business, each having a relationship governed by processes and behaviors governing generative relationships. Each of these relationships should be carefully managed in order to minimize waste and maximize the benefits to productivity enhancing.

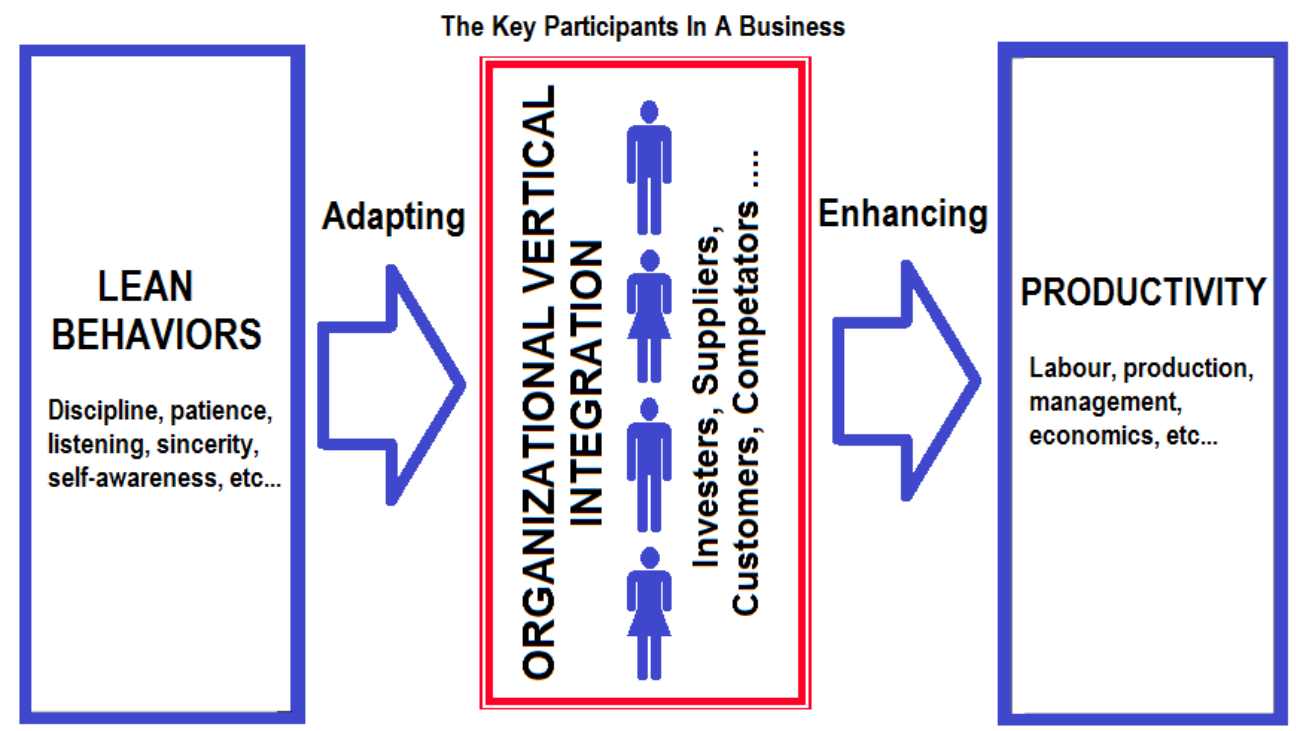

Fig. 1. Enhancing Productivity Through Lean Behaviors In A Business

\section{Background of case study}

The Company where the case study was conducted was incorporated on 16th August 1994. Currently, numbers of employees are 1155 person. The nature of business for this company is to manufacture composites components for aero and non aero structures. The name of this company is changed to $\mathrm{ABC}$ in terms of confidential issues. $\mathrm{ABC}$ was given a mandate by the government to spearhead Malaysia's foray into the high technology industry of aerospace and composites manufacturing.

The objective of the establishment of $\mathrm{ABC}$ is to become the manufacturing arm for $\mathrm{ABC}$ 's work cluster. $\mathrm{ABC}$ created the work cluster with the aim to provide design, manufacturing and aircraft production services to relevant industries. This company fits into the business plan by participating in manufacturing activities for sub-contract work. To date, $A B C$ has succeeded in securing major wing manufacturing programmed with leading aerospace companies, BAE systems, specifically for the manufacture of Airbus A300, A320 and A380 range of aircrafts. The company has also secured non-aerospace composites component manufacturing of the Alvis Bridging Launch Rail in Advance Composites. Within a short span of time since its formation, $\mathrm{ABC}$ has emerged as a leading aerospace company in the 
region and a known industry player in the world. Though $A B C$ having start to implement Lean Manufacturing System since 2004, but there are some mistakes and frailness due to the lack of implementation which is observed as in production system, where the knowledge and understanding of lean manufacturing system as common and primary root cause problem. The whole of problems occurred throughout from the top level to the bottom. Due to this, the top management commitment, teamwork, and people capabilities in eliminating wastages are also lacking. Furthermore, the problems occurred because the lean implementation was not linking to the individual, department, and company's key performance indicator which was unmotivated the total employees of the company to practice the real of lean concepts. Therefore, based on this reality the lean behavior among the employees never rooted. Effectively in the end of 2006, the company overcomes the past problems with new perspective of lean implementation by developing the integration and heuristic approach of lean concepts as a new strategy that involve all aspects of the company in their operation that correlated to the KPI. The scope of study for this project is conducted only at kitting department.

\section{Developing a new system to productivity enhancing}

In today's competitive world, no company can afford to waste resources. The most underutilized resource of most manufacturing company is their people assets. The number one asset of any organization is also its people. In fact, people are one of the few appreciating asset an organization has. The real advantages of employee's involvement are to focus a group of employees with different perspective on a single objective that support the organization's strategic focus. The companies that develop and leverage the capabilities of all their employees will achieve better performance than those that do not. The companies that fail to unlock the potential of their workforce will be forced to carry more overhead, have more layers of management, will be slower to react to market change and opportunities. Therefore, since we implement lean as a system in which the people functions need to be developed into a system which called "People Management Systems" to provide the capability for rapid improvement and adoption to change. Each of the three systems in framework has its own objective. The objective of the lean process management system is to identify and eliminate wastages by removing non value added activities. People management systems need to provide the capability for rapid improvement and adoption to change. Here, again, we must accept the fact that change is inevitable and that the speed with which the necessary modification are made is the deciding factor in our survival. The objective of the business management system is to apply carefully the organization's limited resources, including capital and hard assets as well as time and human assets. Three integration elements with total employee involvement from top to bottom play an important role for sustaining problem solving among employees in practicing lean concept. It is important to create people development system which consists of all these three elements with total involvement of people to increase problem solving capability. People management system, Business management system and lean process management system are integrated by principles that, in a sense, hold them together. These principles are meant to provide a framework (Figure 2) to focus the direction in enhancing productivity and problem solving capability among employees by forming as people development system in lean process management. They are: 
- $\quad$ Key performance indicator - KPI for every level such as company, department, section and individual levels which is linked towards the organization goal.

- $\quad$ Respect for people - Respect for people which mainly focuses on the lean behaviors that each employee in organization should build in their mind.

- Skill and Knowledge - Skill and Knowledge for employees will support them in practicing lean concept effectively and efficiently by utilizing the lean tool and techniques.

Another important element incorporated with this people development system framework is teamwork of top, middle and bottom management. The total commitment of all these three levels will enhance the productivity and the problem solving capability in lean process management among employees.

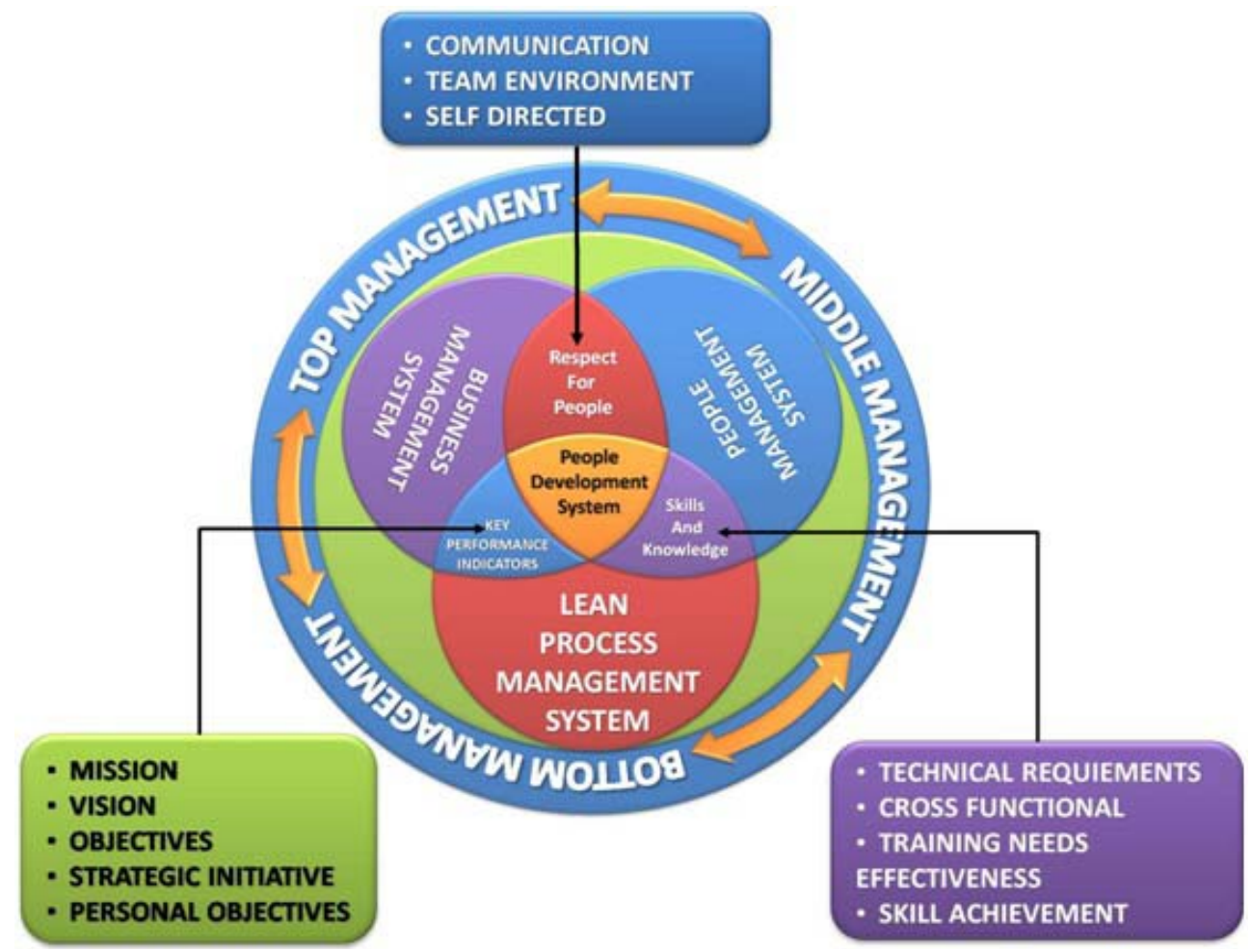

Fig. 2. PDS Framework for Enhancing Productivity and Problem Solving Capabilities Among Employees.

\section{Key characteristic, critical success factors (CSF) and related performance matrix}

The following key characteristics, CSFs and related performance metrics are identified A.P. Puvanasvaran et al (2008), as crucial in people development system of lean process management and are highlighted in Table 2. 
- KPI in lean process management determination through Mission, Core Value, Vision, Objective, Strategy, Strategy Initiative and Personal Objective for people development system is crucial. This will align overall workforce of the company to follow one common goal. Each level has its own portion of contribution towards the target. The results are compared with the target or goal used to measure the success of KPI. The accumulation of success from each portion will reflect the overall achievement of the company goal.

- $\quad$ Respect for people in lean process management is another crucial factor in developing the lean culture throughout organization. In order to measure the lean behaviors, top management commitment, leanness level of the company and perception of team member's capability, Liker (2004) type scale is used to get the responses from respondent. For example, one can ask managers to rate the degree of support by top management on five-point scale from no support (1) to total support (5). Beside this, the problem solving capability also can be measured by counting the number of ideas generated, Level of people involved and the total cost of the project.

- $\quad$ Skill and Knowledge in lean process management is the fundamental requirement for employees to equip themselves. Without this they can't perform well in solving problem to identify and eliminate wastages. Lean tools and assessment techniques by using assessment criteria to determine the level of implementation using spider web chart with rating of 1 (beginning to introduce) to 5 (practice with excellent). Another measurement on employee skill metric will emphasize on employees skill and their cross functionality.

\begin{tabular}{|c|c|c|}
\hline $\begin{array}{l}\text { Key characteristics of } \\
\text { integration elements }\end{array}$ & $\begin{array}{l}\text { Critical success factors (CSF) } \\
\text { of People Development System (PDS) }\end{array}$ & Performance Matrix \\
\hline $\begin{array}{l}\text { KPI } \\
\text { Mission } \\
\text { Core Value } \\
\text { Vision } \\
\text { Objective } \\
\text { Strategy } \\
\text { Strategy In itiative } \\
\text { Personal Objective } \\
\end{array}$ & $\begin{array}{l}\text { Customer Satisfaction } \\
\text { On Time Delivery } \\
\text { Zero Defect } \\
\text { Cost reduction } \\
\text { Effective Operation Cost }\end{array}$ & $\begin{array}{l}\text { Achievements of KPI for each } \\
\text { level versus goal/target. } \\
\text { Productivity } \\
\text { Customer complain } \\
\text { Scrap/Number of reject } \\
\text { Attendance/ Absenteeism } \\
\text { Tardiness (Schedule time) } \\
\text { Using QCDAC principles }\end{array}$ \\
\hline $\begin{array}{l}\text { Respect for people } \\
\text { Team Environment } \\
\text { Self Directed } \\
\text { Communication }\end{array}$ & $\begin{array}{l}\text { Top Management Commitment } \\
\text { Team effectiveness/formation } \\
\text { Ideas cost or value } \\
\text { Continuous improvements } \\
\text { Lean Behaviors } \\
\text { Rewarding system }\end{array}$ & $\begin{array}{l}\text { Number of ideas generated } \\
\text { Level of people involvement } \\
\text { Usage of lean tools } \\
\text { Total cost saving projects } \\
\text { Measured by Likert-type scale on the following items: } \\
\text { Top Management Commitment } \\
\text { Lean behaviors } \\
\text { Achievement of Leanness level }\end{array}$ \\
\hline $\begin{array}{l}\text { Skill and Knowledge } \\
\text { Technical Requirem ents } \\
\text { Cross Functionality } \\
\text { Training Needs \& Effectiveness } \\
\text { Skill Achievement }\end{array}$ & $\begin{array}{l}\text { Produce skilled, knowledgeable } \\
\text { and innovative employees }\end{array}$ & $\begin{array}{l}\text { Lean tools and techniques assessment } \\
\text { Employee skill metric } \\
\text { Audit by } 3^{\text {rd }} \text { party or customers on lean practice }\end{array}$ \\
\hline
\end{tabular}

Table 2. An Analytical Framework For Measuring Problem Solving Capability In Lean Process Management

\section{Methodology}

To conduct the case study survey, the questionnaire was used which was developed by the Ford Motor company. The questionnaires contain the criteria of lean behavior practices based on the literature review Orr (2005). The lean behavior practices are divided into three 
categories which are; respect for people (RFP), continuous learning and improvement (CL\&I) and process and result driven (P\&RD). This is exactly to fulfill the Toyota "4 P model" Orr. For the RFP and CL\&I, there are nine variables asked, and for P\&RD, there are twelve variables to answer. The answers of questionnaire were using the four-point scale and circle the appropriate number. The response scale ranges from 1 to 4 representing the range of strongly agree, agree, disagree, and strongly disagree.

The index value is used to determine the strength and weakness of lean behavior practices. The index value is calculated by formula provided by Nesan and Holt (2002).

$$
\text { Index }=\left[\left(n_{1}\right)+2\left(n_{2}\right)+3\left(n_{3}\right)+4\left(n_{4}\right)\right] /\left[4\left(n_{1}+n_{2}+n_{3}+n_{4}\right)\right],
$$

Where $\mathrm{n}_{1}, \ldots, \mathrm{n}_{4}$ represent the number of respondents that indicated the respective practices on the scale 1 to 4 . The formula yields indices ranging from 0 to 1 , where below 0.2 represent minimum strength and above 0.8 represents maximum strength

Nesan and Holt (2002). The second analysis is to determine the relationship or mean score of each level of management for each practice. Analysis of variance (ANOVA) is used to analyses situations in which there are several independent variables and how these independent variables interact with each other Field. Before calculating the ANOVA, one assumption must be considered is the score of variable is normally distributed. For the third analysis, correlation is used to measure the difference between each principle variables and how are they related. Before calculating a correlation coefficient, there are a few assumptions for correlation analysis which are normality and linearity Coakes (2005). Pearson's correlation coefficient is a measure of linear association with the score for each variable is normal distributed. If the relationship is not linear and normal distributed, Spearman's rho will be used to measure the correlation between the variables Coakes (2005).

\subsection{Pilot test}

Pilot test is conducted to ensure the finding from the questionnaire is valid and meet the objective of this project. This is done by sending the questionnaire to two lean expertise of the company. Discussion on the questionnaire was held when the company was visited. Opinion was given which help researcher to modify the questionnaire. Besides that, from the pre-test, the total time spend to answer the questionnaire also can be identified.

\subsection{Sending and receiving questionnaire}

The questionnaires send to a composite manufacturing company in Malaysia. The questionnaire is directed to three levels of the company, which are, top management, engineers and operators, and shop floor workers. For the top management level respondent, the questionnaires were answered by all department of the company. Meanwhile, the questionnaire only rated by kitting area department for the last two level respondents. The feedback is received within two weeks from the company. The total feedbacks are 53. The questionnaires send to one of composite manufacturing company in Malaysia. The questionnaire is directed to three levels of the company, which are, top management, engineers and operators, and shop floor workers. For the top management level respondent, the questionnaires were answered by all department of the company. Meanwhile, the 
questionnaire only rated by kitting area department for the last two level respondents. The feedback is received within two weeks from the company.

\subsection{Analysis using SPSS}

After getting the result from company, authors will use the software SPSS version 13 to make the analysis. In the 2 part of the question (about lean behavior), the outputs of the analysis were in the form of index values, percentages and hypothesis testing. In the literature review state that Emiliani and Stec (2004) explain lean behavior is applying lean principles and tools to improve leadership behaviors and eliminate behavioral waste.

\section{Results and discussion}

In order to assess the lean behavior before and after the lean implementation, a questionnaire was distributed and then an internal consistency analysis was used to evaluate the reliability of questionnaire.

\subsection{Respondent rate}

The questionnaire distributed directly to the employees to do the survey. The beginning of the year (January) questionnaire was distributed to 45 employees of the kitting department. However, 3 employees already resign. Thus, the questionnaire only assigned by 42 people and the feedback collected exactly 42 respondent results. At the end of the year, questionnaire was distributed to 44 people and collected back exactly 44 responds.

\subsection{Reliability test}

Internal Consistency Analysis: An internal consistency analysis was used to assess the reliability of questionnaire. It is an indicator of how well the different items measure the same issue. The measurement of internal consistency involve for calculation of Cronbanch's coefficient alpha. The values of alpha range from 0 to 1 where the value close to 1 indicate higher reliability. Alpha value should be positive and usually greater than 0.7 which are considered acceptable for testing the reliability of factors. As shown in table 3, the alpha value for the January 2007 in the three categories range is from 0.721 to 0.821 . For respect for People, the scale of reliability can be increased by eliminating Q02 which show 0.815 . For Continuous Learning and Improvement, the scale of reliability it is better to include all of the nine questions and if any questions were eliminated, will reduce the scale reliability. Last but not least for Process and Result Drive, the scale of reliability can be improved by eliminating Q30 which show 0.829. For the December 2007 the alpha value in three categories ranges from 0.718 to 0.758 . For respect for People, the scale reliability can be increased by eliminating Q03 which show 0.739. For Continuous Learning and Improvement \& Process and Result Driven the scale of reliability were reduced Q12 and Q23, which show 0.768 and 0.801 .

Although, the alpha value for the 3 categories for December 2007 is decreased when compare with January 2007, but the range is greater than 0.7 , so the instrument are consider acceptable. Furthermore, the elimination questions are not necessary as the alpha value increase slightly after eliminating. Since the alpha value are greater than 0.7 , it can conclude that this instrument is reliable. 


\begin{tabular}{|c|c|c|c|}
\hline Scale & $\mathrm{N}$ of items & Alpha if deleted & Alpha if deleted \\
\hline Respect for People, Alpha $(\mathrm{Jan}=0.790, \mathrm{Dec}=0.718)$ & 9 & - & \\
\hline Q01 & & 0.761 & 0.713 \\
\hline Q02 & & 0.815 & 0.692 \\
\hline Q03 & & 0.763 & 0.739 \\
\hline Q04 & & 0.743 & 0.708 \\
\hline Q05 & & 0.769 & 0.683 \\
\hline Q06 & & 0.733 & 0.658 \\
\hline Q07 & & 0.793 & 0.639 \\
\hline Q08 & & 0.770 & 0.695 \\
\hline Q09 & & 0.760 & 0.699 \\
\hline Continuous Learning and Improvement, Alpha $($ Jan $=0.721$, Dec $=0.747)$ & 9 & - & \\
\hline Q10 & & 0.705 & 0.678 \\
\hline Q11 & & 0.681 & 0.767 \\
\hline Q12 & & 0.709 & 0.768 \\
\hline Q13 & & 0.668 & 0.730 \\
\hline Q14 & & 0.681 & 0.717 \\
\hline Q15 & & 0.708 & 0.703 \\
\hline Q16 & & 0.713 & 0.698 \\
\hline Q17 & & 0.673 & 0.702 \\
\hline$\underline{Q} 18$ & & 0.719 & 0.742 \\
\hline Process and Result Driven, Alpha (Jan $=0.821$, Dec $=0758)$ & 12 & - & \\
\hline Q19 & & 0.817 & 0.785 \\
\hline Q20 & & 0.799 & 0.757 \\
\hline Q21 & & 0.782 & 0.750 \\
\hline Q22 & & 0.812 & 0.757 \\
\hline Q23 & & 0.792 & 0.801 \\
\hline Q24 & & 0.793 & 0.769 \\
\hline Q25 & & 0.792 & 0.766 \\
\hline Q26 & & 0.795 & 0.771 \\
\hline Q27 & & 0.825 & 0.803 \\
\hline Q28 & & 0.825 & 0.763 \\
\hline Q29 & & 0.815 & 0.768 \\
\hline $\mathrm{Q} 30$ & & 0.829 & 0.758 \\
\hline
\end{tabular}

Table 3. Reliability Statistic January 2007 and December 2007

\subsection{Analysis and results}

The structured postal questionnaire survey was designed to assess initial literature search finding concerning the 30 practices, in two different dimensions. Dimension 1 investigated 
the strength and weakness of lean behavior practices within the organization. Dimension 2 explored the relationship between the lean principles. For each dimension, four Likert (2004) scales ranging from 1 to 4 were provided and the scale was used is the agreement scale. Agreement scale is used to determine agreement on of the 30 lean behaviors practices, the scale ranged from 1 (strongly disagree) to 4 (strongly agree).

\subsection{Analysis of strength and weakness of the lean behaviors practice}

Data obtained from the survey were subjected to relative index calculations for agreement factor. The relative index was calculated by using the formula:

$$
\text { Index }=\left[\left(n_{1}\right)+2\left(n_{2}\right)+3\left(n_{3}\right)+4\left(n_{4}\right)\right] /\left[4\left(n_{1}+n_{2}+n_{3}+n_{4}\right)\right],
$$

Where $\mathrm{n}_{1}, \mathrm{n}_{2}, \mathrm{n}_{3}, \mathrm{n}_{4}$ represent the number of respondents that indicated the respective practices on the scale 1 to 4 . The formula yields indices ranging from 0 to 1 , where below 0.2 represent minimum strength and above 0.8 represents maximum strength Nesan and Holt (2002). From the table 4, the indices calculated for all of the lean practices showed a similar pattern, with indices ranging between 0.464 and 0.78 for January 2007. For the December 2007, the range is between 0.597 and 0.818 . In addition, the min index for 30 practices also increased from 0.691 to 0.7614 , total increments is about $10 \%$. This indicates that lean behavior practices in aerospace composite manufacturer are improved, and it is near to the lean behavior standard. After comparing the 2 group of index, we found that the index for the practices is increased a lot. Such are:

- $\quad$ Meetings start on time. +0.215

- $\quad$ People from outside areas help to solve problems. +0.207

- $\quad$ People share ideas and knowledge.+0.151

However, there is also some practices need to be improved where the indices show dropped. Such practices are:

- $\quad$ People contribute openly and honestly in the meetings I attend.-0.029

- People are coached and trained by their leaders/Supervisors.-0.017

- $\quad$ People deliver what was promised.-0.013

Basically, for the new result, many performances were practiced very well. It can be seen clearly In Figure 3 and the sum of index of practices is increased a lot and meets the lean behavior standard (0.800) already. The results are better if compared with the January 2007 which is totally negative and only one practice meet the lean behaviors standard. Below are the practices that meet the standard:

- $\quad$ Before making decisions, people gather the information -from 0.708 to 0.818

- People share ideas and knowledge-from 0.667 to 0.818

- People are encouraged to improve their knowledge and skills at work -0.738 to 0.813

- People look for ways to improve their work -from 0.750 to 0.801

- People focus on the customer and the customer need (inside and outside the plant) from $0.750-0.818$.

However, one of the practices that needs improvement and need to be given more attention is the indices showed very low. The practice is: 


\begin{tabular}{|c|c|c|c|c|c|c|}
\hline Questions & Sum & Sum & Index & Index & Rank & Rank \\
\hline 1 & 121 & 126 & 0.720 & 0.716 & 14 & 27 \\
\hline 2 & 127 & 128 & 0.756 & 0.727 & 3 & 24 \\
\hline 3 & 111 & 128 & 0.661 & 0.727 & 23 & 24 \\
\hline 4 & 116 & 134 & 0.690 & 0.761 & 19 & 18 \\
\hline 5 & 119 & 144 & 0.708 & 0.818 & 17 & 1 \\
\hline 6 & 106 & 135 & 0.631 & 0.767 & 26 & 15 \\
\hline 7 & 116 & 137 & 0.690 & 0.778 & 19 & 11 \\
\hline 8 & 88 & 130 & 0.524 & 0.739 & 29 & 22 \\
\hline 9 & 110 & 131 & 0.655 & 0.744 & 24 & 20 \\
\hline 10 & 112 & 144 & 0.667 & 0.818 & 21 & 1 \\
\hline 11 & 78 & 105 & 0.464 & 0.597 & 30 & 30 \\
\hline 12 & 126 & 129 & 0.750 & 0.733 & 4 & 23 \\
\hline 13 & 122 & 140 & 0.726 & 0.795 & 12 & 6 \\
\hline 14 & 124 & 143 & 0.738 & 0.813 & 7 & 4 \\
\hline 15 & 123 & 140 & 0.732 & 0.795 & 10 & 6 \\
\hline 16 & 124 & 135 & 0.738 & 0.767 & 7 & 15 \\
\hline 17 & 95 & 136 & 0.565 & 0.772 & 28 & 14 \\
\hline 18 & 123 & 137 & 0.732 & 0.778 & 10 & 11 \\
\hline 19 & 122 & 140 & 0.726 & 0.795 & 12 & 6 \\
\hline 20 & 118 & 137 & 0.702 & 0.778 & 18 & 11 \\
\hline 21 & 121 & 140 & 0.720 & 0.795 & 14 & 6 \\
\hline 22 & 124 & 140 & 0.738 & 0.795 & 7 & 6 \\
\hline 23 & 130 & 131 & 0.774 & 0.744 & 2 & 20 \\
\hline 24 & 126 & 141 & 0.750 & 0.801 & 4 & 5 \\
\hline 25 & 120 & 133 & 0.714 & 0.756 & 16 & 19 \\
\hline 26 & 108 & 125 & 0.643 & 0.710 & 25 & 29 \\
\hline 27 & 112 & 127 & 0.667 & 0.722 & 21 & 25 \\
\hline 28 & 104 & 126 & 0.619 & 0.716 & 27 & 26 \\
\hline 29 & 131 & 135 & 0.780 & 0.767 & 1 & 15 \\
\hline 30 & 126 & 144 & 0.750 & 0.818 & 4 & 1 \\
\hline
\end{tabular}

Table 4. Strength Values For January 2007 and December 2007 
- Plant leadership is on the plant floor daily to provide assistance and improve the business is 0.597 . However; the index also improved already, for the Jan 2007 just 0.464

Beside the index, after comparing the 2 group of ranking the authors found that the ranking for the practices also change drastically. These are:

- People share ideas and knowledge, it is raise 20 rank, from ranking 21 raise to 1 . It is the biggest lift practices:

- Before making decisions, people gather information. It is raise to 16 rank, from ranking 17 raise to 1 .

- $\quad$ People from outside help to solve the problem. It is raised 14 rank, from ranking 28 raise to 14 .

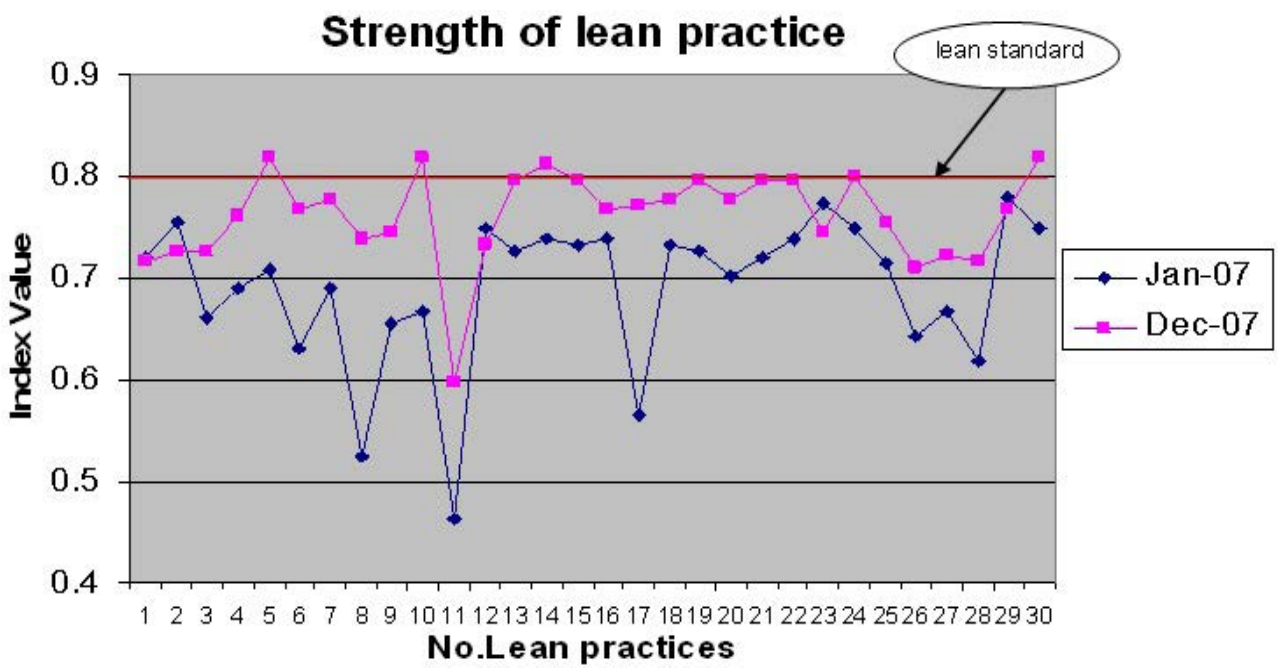

Fig. 3. Strength of Lean Practices.

The result at Table 5 shows that the increment respects for people was the highest. The practices for RFP such as, people contribute openly and honestly in the meeting will give employees operational autonomy encouraged an innovative culture and let employee contribute more ideas to solving problems. Furthermore, the practices "people can participate in decision relevant to their job and focus on the problem" in RFP also got strong relationship with PSC. In a study among the employees of a manufacturing plant, it found a positive relationship between participation and employees' innovative behavior, measured using self-ratings of employees' suggestions and implementation efforts will contribute to the idea of solving problem.

\begin{tabular}{lll}
\hline Construct & Jan 2007 & Dec 2007 \\
\hline Respect for people ( RFP) & 0.67 & 0.773 \\
Continuous learning and improvement (CLAI) & 0.679 & 0.763 \\
Process and result Driven (PARD) & 0.653 & 0.698 \\
\hline
\end{tabular}

Table 5. Analysis Mean Value Index RFP, CLAI, PARD. 
The Figure 4 shows that index value of three main categories which all have significant increase. Especially, respect for people, which is increased from 0.67 to 0.773 . This is followed by continuous learning and improvement raised from 0.679 to 0.763 and the process and results driven shows improvement from 0.653 to 0.698 in each. Overall the results shows the company improved in all 3 construct, Thus, we can say, the company really put a lot of effort in practices lean behavior as shown in the comparison of lean behaviors in Table 8 and Figure 5. In conclusion, authors found that most practices of the lean behavior will improve the PSC of the employee. Thus, after implementing lean process after one year, problem solving capability of employee had been increased and make the lean result of company increase.

\section{Lean Behavior}

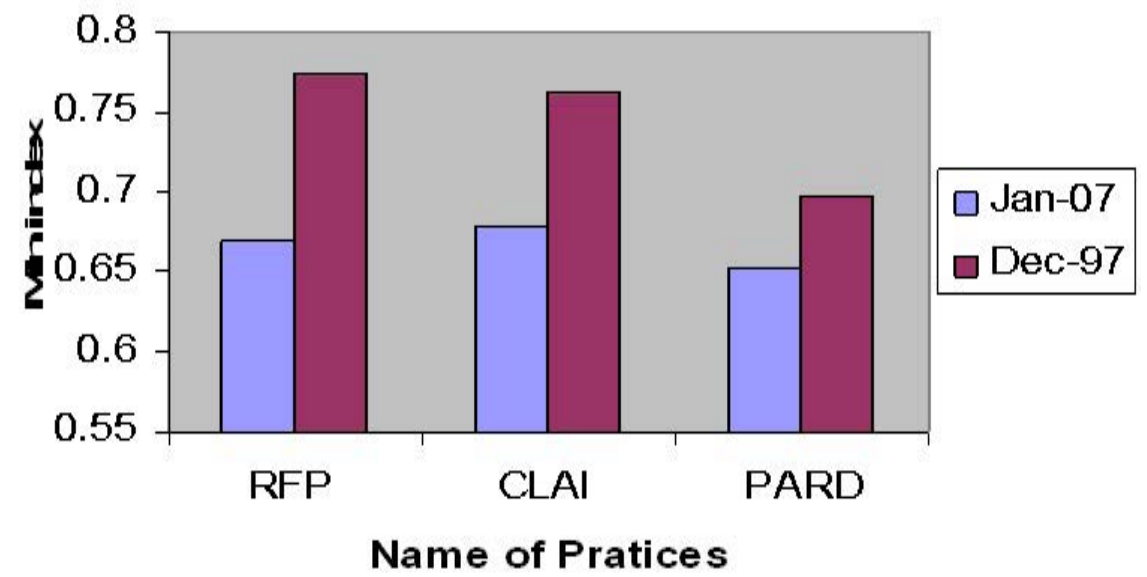

Fig. 4. Lean Behaviors Index Value

\subsection{Analysis of the relationship between the lean principles}

Correlation between Respect for People, Continuous Learning and improvement and Process and Result Driven are shown in Table 6 and Table 7. The data obtained was analyzed by using Statistical Package for Social Science (SPSS) software version 13. Correlation method was used where correlation is a measure of relationship involving variables Field. Table 6 and Table 7 show a matrix that is displayed giving the correlation between the three variables. For the January 2007correlation coefficient 0.587 between

\begin{tabular}{|c|c|c|c|c|}
\hline & & $\begin{array}{l}\text { Respect for } \\
\text { People }\end{array}$ & $\begin{array}{l}\text { Continuous Learning } \\
\text { and improvement }\end{array}$ & $\begin{array}{l}\text { Process and } \\
\text { Result Driven }\end{array}$ \\
\hline \multirow[t]{2}{*}{ Respect for People } & Correlation coefficient & 1.000 & $0.456^{* *}$ & $0.562 * *$ \\
\hline & Significant value & - & 0.001 & 0.000 \\
\hline \multirow[t]{2}{*}{ Continuous Learning and improvement } & Correlation coefficient & $0.456^{* *}$ & 1.000 & 0.193 \\
\hline & Significant value & 0.001 & - & 0.111 \\
\hline \multirow[t]{2}{*}{ Process and Result Driven } & Correlation coefficient & $0.562 * *$ & 0.193 & 1.000 \\
\hline & Significant value & 0.000 & 0.111 & - \\
\hline
\end{tabular}

Table 6. Correlation between Factors In January 2007. 
Respect for People and Continuous Learning and Improvement is 0.456 , and the significance value of this coefficient is 0.001 . But for December 2007, the values become 0.129 , and significance value is 0.202 while the correlation coefficient between Respect for People and Process and Result Driven is 0.526 with the significance value is 0 . But for new result it is 0.101 and the significance value is 0.258 .last but not least, correlation coefficient between Continuous Learning and improvement and Process and Result Driven is 0.193 with the significance value is 0.111 . For new result is 0.310 and 0.020 .

\begin{tabular}{|c|c|c|c|c|}
\hline & & $\begin{array}{l}\text { Respect for } \\
\text { People }\end{array}$ & $\begin{array}{l}\text { Continuous Learning } \\
\text { and improvement }\end{array}$ & $\begin{array}{l}\text { Process and } \\
\text { Result Driven }\end{array}$ \\
\hline \multirow[t]{2}{*}{ Respect for People } & Correlation coefficient & 1.000 & $0.587^{* *}$ & 0.101 \\
\hline & Significant value & - & 0.001 & $0.258^{*}$ \\
\hline \multirow[t]{2}{*}{ Continuous Learning and improvement } & Correlation coefficient & $0.587 * *$ & 1.000 & 0.310 \\
\hline & Significant value & 0.001 & - & 0.020 \\
\hline \multirow[t]{2}{*}{ Process and Result Driven } & Correlation coefficient & 0.101 & 0.310 & 1.000 \\
\hline & Significant value & $0.258^{*}$ & 0.020 & - \\
\hline
\end{tabular}

Table 7. Correlation between Factors In December 2007

\begin{tabular}{lll}
\hline Variable & Index (Jan) & Index (Dec) \\
DOB & 0.691 & 0.7164. \\
\hline
\end{tabular}

Table 8. Index Value of Lean Behavior In January 2007 and December 2007

Comparison for Lean behaviors

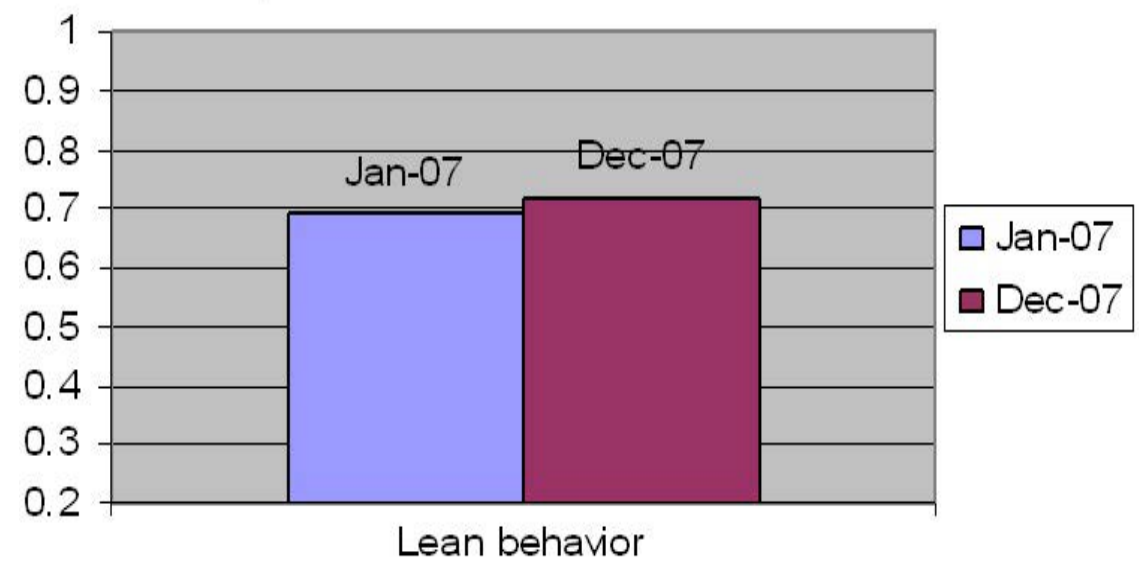

Fig. 5. Comparison for Lean Behaviors.

\section{Success of people development system in case study company}

The importance of problem solving capabilities of every employee in implementing lean process management to make the improvement in lean behaviors is evident as depicted by the real life data of kitting department as the company case study. 


\subsection{Idea generated and level of involvement}

Many studies focus mainly on the creative or idea generation stage of problem solving. In this context, employees can help to improve business performance through solving problem, such as generating ideas and use them as building blocks for new and better products, services and work processes Joreon. P.j.de.long (2007). From the graph shown below, every week at least one idea had been generated in kitting department, and the highest is 5 ideas generated per week. In past one year, a total of 139 ideas have been generated .It is proved that kitting department proactively and continually sought ideas to solve problems, indicates that employees have the capability to solve problem to become a central tenet of lean manufacturing best practice Kerrin (1999).

The employee involvement is categorized according to three main levels which are top, middle and bottom management. The Figure 6 below shows the level of involvement of employees by generating ideas for the year 2007. The highest contribution is coming from bottom level which is 38 and followed by middle level with 12 to top level which is 2 . Besides this, there is also a combination level involvement in generating ideas. Bottommiddle level is 52 , middle-top is 35 and bottom-top is 1 . Furthermore, total idea generated for group combination level is 87 and single group level is 52. The percentage for combination level is $63 \%$ for total ideas generated and 3 type levels is $37 \%$. However if we compare 2 groups, the result shows that total idea generated by group combination level is 35 more than single group level. Thus, the result indicates the teamwork of bottom; middle and top management in both sharing and applying knowledge for generating ideas in solving problems that are important Delbridge et al (1998).

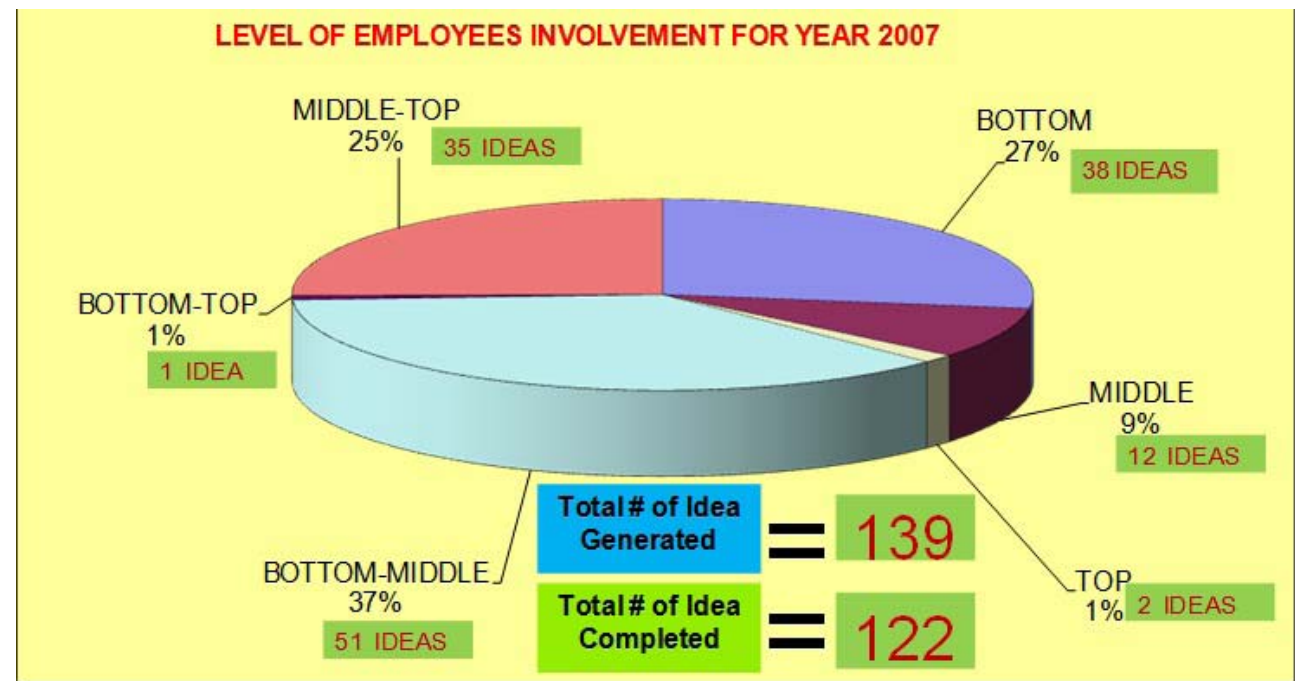

Fig. 6. Level of Employee's Involvement for Year 2007

\subsection{Total of wastages}

The graph at Figure 7 gives us an idea about type of wastages identified at the kitting department, where it is classified into 9 categories. It is obviously noted that the highest 
waste for company is the waste of space which is 39 , the second one is time waste at 21 , and the lowest waste is transportation which is at 5 . Without classification of any wastage into performance measurement, no monitoring can be made and no problem solving can be done to reduce the waste, where the impact is the failure of lean process management implementation A.P. Puvanasvaran et al (2008). It indicates that the employees of the company have capabilities to solve waste problem using the performance measurement.

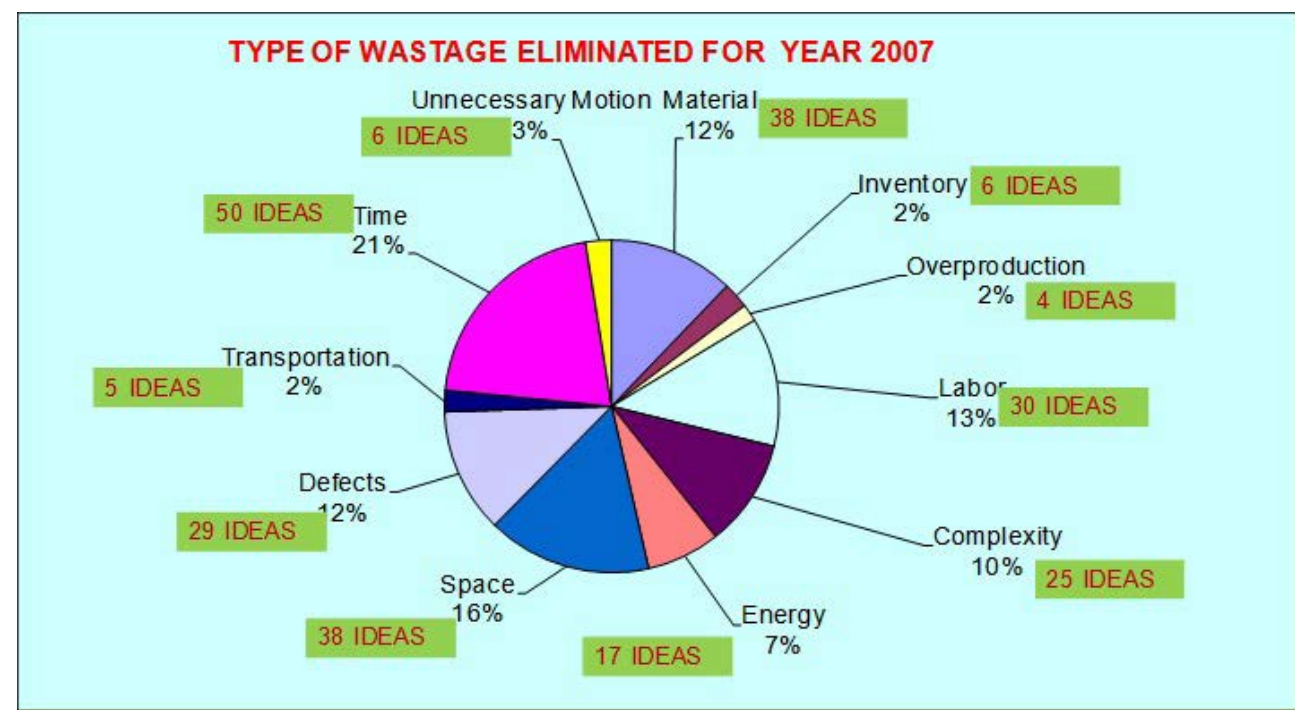

Fig. 7. Type of Wastage Eliminated for Year 2007.

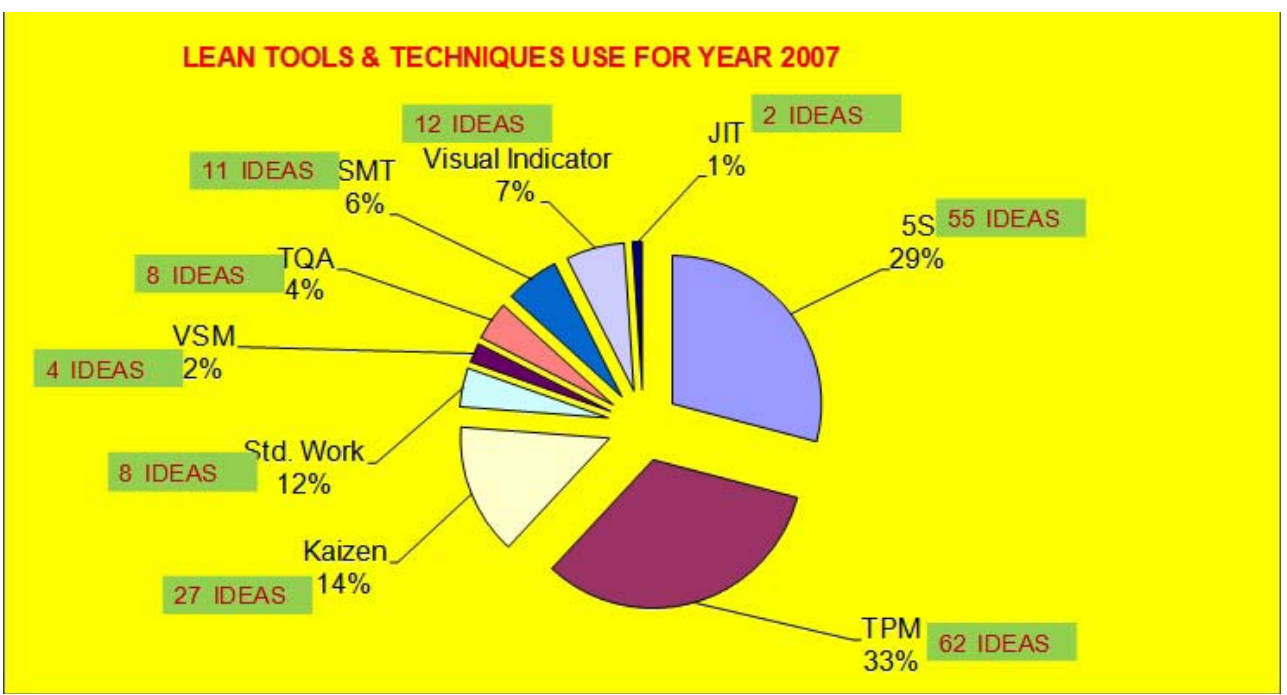

Fig. 8. Lean Tool and Techniques Use for Year 2007. 


\subsection{Cost saving}

Cost saving is an important standard to indicate the problem solving capability of the organization. The aim of lean manufacturing is elimination of waste in every area of production and includes customer relations, product design, supplier networks, and factory management. To meet the objectives of saving cost, Womack and Jones (1996). Kitting department ran a Kaizen Project in 2007, and the total amount of saving for reduces wastages in past one year is RM1, 952,617.98. Thus, achievement of cost saving for company indicates employee had contributed most of the solutions to solve the problem of waste. So, it can be construed that problem solving capability of employees actually improved significantly. The Table 9 indicates total cost savings of the kitting department with the reference to their kaizen project generated form the problem solving activities.

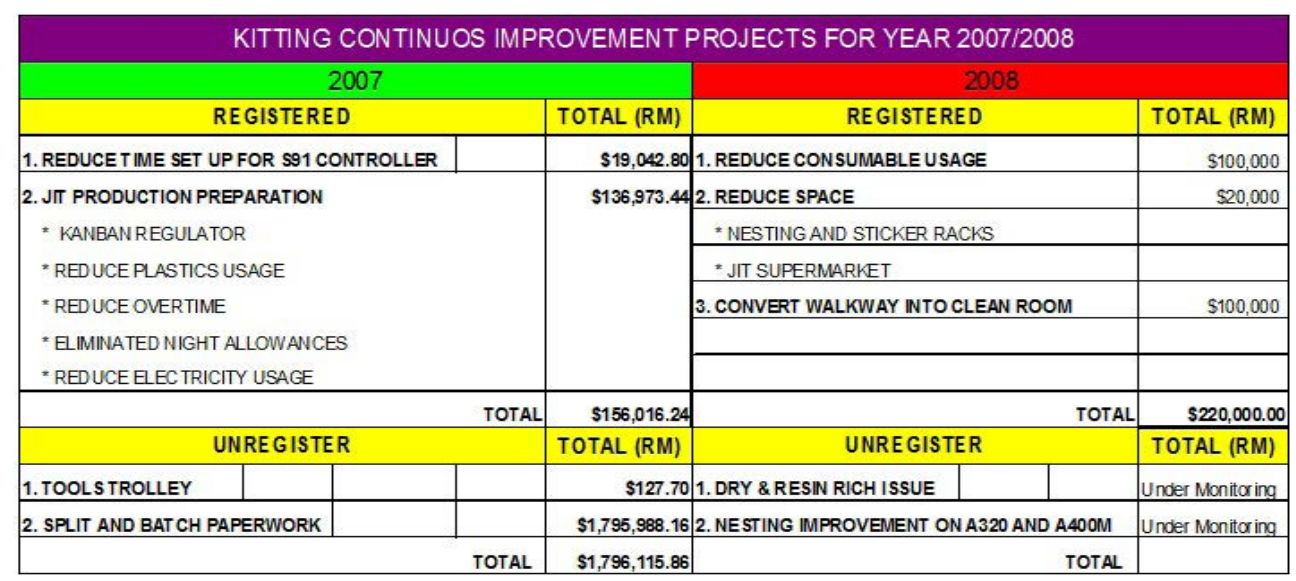

Table 9. Continuous Improvement Projects for the Year 2007 and 2008. 


\section{Lean tools used in problem solving and productivity enhancing}

In general, lean tool for kitting department can be categorize to 9 types as shown in Figure 8, such as five $S$, total productive maintain, Kaizen, visual stream map, visual indicator, just in time, and standard work chart. The most common tool used by kitting department is TPM, which is 62 times, followed by $5 \mathrm{~s}, 55$ time and mean values of using lean tool is 21 times. In the past one year, the kitting department total used 189 times of lean tool. In order to introduce lean thinking within manufacturing environment, the philosophy relies on the identification and elimination of the waste problem, which have effectively targeted and applied the various lean tools B.J. Hicks (2007). Thus, the frequency of employee using the lean tool indicates employee understanding identification and elimination of waste problem. In deduction, the employees have capability of problem solving.

\section{KPI achievement}

KPI is an important element that enables the achievement of vision, mission, core value, strategy, and the personnel objective for people development is crucial. Achievement of KPI shows the evidence of people involvement to drive high performance to gain stakeholder and customer satisfaction. Monitoring on each performance, measurement and countermeasurement taken to solve any problem occurring have contributed to the achievement of KPI.

The Table 10 shows total monthly man hours percentage of Overtime at kitting department has set the limit to be below $12 \%$ for the year 07. During PDS implementation, overtime was controllable all the time; not even a month exceeded the limit of overtime, which eventually gave a value of $11.5 \%$ for the whole year. It indicates that the company has saved considerably on labors cost in the past one year. The cost saving is due to employee success in lowering the stop time for the machine DCS 1, DCS 2, DCS 3.

\begin{tabular}{|c|c|c|c|c|}
\hline Principles & Matrix & Unit & Goal/Limit & $\begin{array}{c}2007 \\
\text { Achievement }\end{array}$ \\
\hline \multirow{4}{*}{ Quality } & Scrap & $\mathrm{MQ} \%$ & $2.60 \%$ & $1.97 \%$ \\
\hline & NCR & $\%$ & $7.80 \%$ & 0 \\
\hline & Snag Sheet & Control Limit $\%$ & $20 \%$ & 0 \\
\hline & Audit & \# of CAR & Zero & 1 \\
\hline \multirow{6}{*}{ Cost } & Overtime & $\begin{array}{c}\text { Total Monthly man } \\
\text { hours } \%\end{array}$ & $12 \%$ & $10.50 \%$ \\
\hline & Downtime & $\%$ & $10 \%$ & \\
\hline & DCS 1 & $\%$ & $10 \%$ & $9.14 \%$ \\
\hline & DCS 2 & $\%$ & $10 \%$ & $8.80 \%$ \\
\hline & $\operatorname{DCS} 3$ & $\%$ & $10 \%$ & $7.65 \%$ \\
\hline & S91 & $\%$ & $10 \%$ & $10.34 \%$ \\
\hline Delivery & Output & $\%$ & $97 \%$ & $100 \%$ \\
\hline \multirow{5}{*}{ Accountability } & Attendance & $\%$ & $92 \%$ & $90.7 \%$ \\
\hline & Training & Hours & 18shrs & 2314hrs \\
\hline & Stafftrg hours & $\%$ & 47 staff & $100 \%$ \\
\hline & Major Accidents & Qty accidents & Zero & 0 \\
\hline & Accident Free Days & \# of days & 90days & 365 \\
\hline \multirow{3}{*}{$\begin{array}{l}\text { Continuous } \\
\text { Improvement }\end{array}$} & Kaizen & $\mathrm{RM}$ & $150 \mathrm{~K}$ & $156 \mathrm{~K}$ \\
\hline & SMT & Level & Level 4 & L4 \\
\hline & $5 \mathrm{~S}$ & Level & Level 4 & L4 \\
\hline
\end{tabular}

Table 10. KPI Achievement. 
The table also shows the achievement for the value scrap is $1.97 \%$ which achieved the goal of $2.6 \%$. The reason why the value is achieved is because the employees use the PDS methods to solve many scrap problems such as material dry and ply damage for the whole year. Complaints on product produce from internal and external customer shows null. It shows that quality of kitting department undergone significant upgrading due to problem solving capability of employees.

The Kitting department of the Company has gained benefits from many elements that have not been monitored before, the implementation of PDS. Wastages have reduced dramatically. Thus, the achievement KPI proves that productivity and problem solving capability has increased.

\section{Conclusion}

The purpose of this project has been to evaluate the improvement for the lean behavior possessed by the company in past one year. It reflects the enhancing productivity through lean behavior. The result show lean practices had been making improvement of the company in lean direction and important of problem solving capabilities in eliminating waste and saving cost thus, enhancing productivity. The results have provided support to the two proposed hypotheses. Besides that, evidence was found to support the relation between improvements of kitting department with problem solving capability on enhancing productivity through lean behaviors of employees in the organization.

The main findings show that the company is improving in past one year. Initial result of the kitting department was in moderate level stage to become lean, but result at the end of the year showed that they had nearly meet the high level stage of lean they need to keep their efforts in order to have productivity success in lean manufacturing implementation. It is also helpful to the company to recognize the importance of increased problem solving capability and productivity enhancing for employee to eliminate waste by adapting lean behaviors. In short, we are all looking toward "Better Productivity Through Better Lean Behavior".

\section{References}

[1] Puvanasvaran, A.P., B.H. Tan, M.H.M.A. Megat, Tang S.H, Muhamad, M.R, A.M.S. Hamouda, 2008c. "Degree Of Leanness And Managerial Commitment In An Aerospace Company" Journal of Statistics and Management System, Vol. 11, No. 4, pp. 653-673, ISSN 0972-0510, Taru Publications, India.

[2] Puvanasvaran, A.P., M.H.M.A. Megat, Tang S.H, Muhamad, M.R, A.M.S. Hamouda, 2008a. "A Review of Problem Solving Capabilities in Lean Process Management" American Journal of Applied Sciences Vol.5 No. 5, 2008,ISSN 1546-9239 @ 2008 Science Publications, pp: 504-511.

[3] Puvanasvaran, A.P., M.H.M.A. Ooi, Megat, S.H. Tang, M.R. Muhamad, A.M.S. Hamouda, 2008b. "Lean Behavior Among Employees In Aerospace Company" 
Journal of Productivity, National Productivity Centre, Petaling Jaya, Malaysia, 25 pp: 29-44.

[4] Anon, 1997. "Case study: Guiding cultural change at Motorola", Management Development Review, 10(4/5): 185-187.

[5] Bhasin, S. and P. Burcher, 2006. "Lean viewed as a philosophy", Journal of Manufacturing Technology Management, 17(1): 56-72.

[6] Cleary, T. (1989), Zen Lessons - The Art of Leadership, Shambhala, Boston, MA.

[7] Cleary, T. (1996), The Human Element, Shambhala, Boston, MA.

[8] Coakes, S.J., 2005. SPSS: Analysis without Anguish-version 12.0 for Windows, John Wiley \& Sons Australia. Ltd, Queensland.

[9] Comm, C.L., 2005. "A case study in applying lean sustainability concepts to universities", International Journal of Sustainability in Higher Education, 6(2): 134146.

[10] Delbridge, R., 1998. “Life on the Line in Contemporary Manufacturing," International Journal of operation \& Production Management, Oxford University Press, Oxford.

[11] Emiliani, M.L. and D.J. Stec, 2004. "Leaders lost in transformation", Leadership and Organization Development Journal, 26(5): 370-387.

[12] Emiliani, M.L., 1998. "Lean behaviors”, Management Decision, 36/9, pp: 615- 631.

[13] Field, A., 2005. “Discovering Statistics Using SPSS", Sage Publications, pp: 107.

[14] Hicks, B.J., 2007. "Understanding and eliminating waste" international Journal of information Management.

[15] Jeroen, P.J. and N.D.H. Deanne, 2007. “How leaders influence employees' innovative behavior. Emerald Group Publishing Limited, pp: 761-771.

[16] Kerrin, N., 1999. Managing Innovation and Change: A Critical Guide for Organizations, Thomson, London.

[17] Liker, J.K., 2004. The Toyota Way: 14 Management Principles from the World's Greatest Manufacturer. McGraw Hill: New York.

[18] Nesan, L., Jawahar and D. Holt Gary, 2002.“ Assessment of organizational involvement in implementing empowerment ", Integrated Manufacturing Systems, 13/4, pp: 201-211.

[19] O'hEocha, C., 2000. "Case studies: A study of the influence of company culture, communications and employee attitudes on the use of 5Ss for environmental management at Cooke Brothers Ltd", The TQM Magazine, 12.(5): 321 \pm 330 .

[20] Orr, C., 2005. "Lean Leadership in Construction", Management of People and Team, Proceedings IGLC-13.

[21] Ronald, M. Becker, 2001. "Automotive Manufacturing and Production " , http://www.findarticles.com/p/articles/mi_m0FWH/is_6_113/ai_76445159 (accessed on June 2001).

[22] Sanjay Bhasin \& Peter Burcher, 2006. "Lean viewed as a philosophy", Journal of Manufacturing Technology Management, 17 (1): 56-72.

[23] Womack, J.P., D.T. Jones, 1996. "Lean Thinking", Emerald Group Publishing Studies, 30(5): 739-58. 
[24] Worley, J.M. and T.L. Doolen, 2006. "The role of communication and management support in a lean manufacturing implementation", Management Decision, 44 (2): 228-245.943 
(C) 2012 The Author(s). Licensee IntechOpen. This is an open access article distributed under the terms of the Creative Commons Attribution 3.0 License, which permits unrestricted use, distribution, and reproduction in any medium, provided the original work is properly cited. 